\title{
The concept of prevention: a good idea gone astray?
}

\author{
B Starfield, ${ }^{1} \mathrm{~J} \mathrm{Hyde}^{2,3} \mathrm{~J} \mathrm{Gérvas,}^{4,5}$ । Heath ${ }^{6}$
}

1 Johns Hopkins University, Baltimore, MD, USA; ${ }^{2}$ Victoria Department of Human Services, Melbourne, Australia; ${ }^{3}$ Monash University, Melbourne, Australia;

${ }^{4}$ Equipo CESCA, Madrid, Spain;

${ }^{5}$ Canencia de la Sierra (Madrid),

Spain; ${ }^{6}$ Caversham Group

Practice, London, UK

Correspondence to:

Dr B Starfield, Professor of

Health Policy, 624 N Broadway, room 452, Johns Hopkins

University, Baltimore, MD

21205-1990, USA;

bstarfie@jhsph.edu

Accepted 9 December 2007

\section{ABSTRACT}

Over time, the definition of prevention has expanded so that its meaning in the context of health services is now unclear. As risk factors are increasingly considered to be the equivalent of "diseases" for purposes of intervention, the concept of prevention has lost all practical meaning. This paper reviews the inconsistencies in its utility, and suggests principles that it should follow in the future: a population orientation with explicit consideration of attributable risk, the setting of priorities based on reduction in illness and avoidance of adverse effects, and the imperative to reduce inequities in health.

The scope of prevention has changed over time. A 1967 textbook stated: "Prevention, in a narrow sense, means averting the development of a pathological state. In a broader sense, it includes all measures-definitive therapy among themthat limit the progression of disease at any stage of its course". ${ }^{1}$ A distinction was made between interventions that avert the occurrence of disease (primary prevention) and interventions that halt or slow the progression of a disease or its sequelae at any point after its inception (secondary prevention).

By 1978, the distinctions between types of prevention had expanded to include primary prevention to promote health prior to the development of disease or injuries; secondary prevention to detect disease in early (asymptomatic) stages; and tertiary prevention to reverse, arrest or delay progression of disease. ${ }^{2}$

Neither the 1967 nor the 1978 definitions used the terminology of "risk factor", but in 1998, the World Health Organization, in addressing "disease" prevention, stated that it "covers measures not only to prevent the occurrence of disease, such as risk factor reduction, but also to arrest its progress and reduce its consequences once established". The Australian National Public Health Partnership designated prevention as "action to reduce or eliminate or reduce the onset, causes, complications, or recurrence of disease". ${ }^{3}$ Several levels were defined: primordial prevention ("preventing the emergence of predisposing social and environmental conditions that can lead to causation of disease; primary prevention; secondary prevention; and tertiary prevention to improve function, minimise impact, and delay complications").

The Dictionary of Public Health defined prevention similarly, but conceded that the distinction between levels "is more artificial than real". ${ }^{4}$

A recent addition to the lexicon of prevention is "quaternary prevention". The world organisation of family physicians (WONCA) defined quaternary prevention as "an action taken to identify a patient at risk of over-medicalization, to protect him (sic) from new medical invasion, and to suggest to him (sic) interventions which are ethically acceptable". ${ }^{.}$ Gofrit et al. defined quaternary prevention as "debriefing, quality assurance, and improvement processes", which "complete the cycle of prevention by collecting information about the processes, multi-disciplinary analysis of the data, deriving conclusions, and distributing them to all the involved bodies". 6

Quaternary prevention has also been defined by cardiovascular disease experts as "rehabilitation or restoration of function", applicable to "those with severe cardiovascular dysfuntion". These three definitions are not easily compatible.

Identification of "risk factors" as part of prevention has been designated a new era in public health and clinical medicine $e^{8}$ and as a new professional activity of epidemiologists. ${ }^{9}{ }^{10}$ Risk factors, such as elevated blood pressure, are now even considered as "diseases". ${ }^{11}$

The shift from public health to clinical disease is evident in the historical development of the concept of prevention. Geoffrey Rose provided the basis for a population orientation to reducing risk factors associated with coronary heart disease, arguing that only a small proportion of cardiovascular events occur in individuals with high risk scores. He maintained that population-based prevention must be low cost, minimally invasive and avoid discomfort and pain. His arguments have been used in ways never intended: to justify treatment of individuals in clinical settings. ${ }^{12}$ This reflects the emergence of the concept of "preventive medicine", particularly in the US. Clinical medicine, while increasingly adopting prevention as a field of activity, lacks a definition of prevention: the Guide to Clinical Preventive Services (US Task Force on Prevention) does not offer one despite increasing confusion about the boundaries between the different levels of prevention. The World Health Organization did not include the term "prevention" as a function of health systems, which are defined as "all the activities whose primary purpose is to promote, restore, and maintain health". ${ }^{13}$

Is the concept of "prevention", with its increasing focus on particular diseases and risk factors (rather than on ill health in general), still useful? When so many people lack adequate access to medical care for their manifest health needs, is it justifiable that routine disease check-up visits are approaching half of all medical visits, as in the United States? ${ }^{14-16}$ Is intervention with four drugs, lifestyle advice and cardiac rehabilitation really prevention, as suggested by the title of a published study "Secondary prevention for patients after a myocardial infarction: summary 
of NICE guidelines"? ${ }^{17}$ Is intervention to reduce the blood level of a known "risk factor" (eg homocysteine) really prevention when it does not reduce the occurrence of the disease or improve overall health $?^{18}$ Should controlling risk factors replace the conventional focus on controlling disease, even if it does not necessarily improve health? Should medication (eg cerivastatin) to improve surrogate outcomes in cardiovascular trials ${ }^{19} 20$ be considered "prevention" when its use is associated with fatal rhabdomyolisis causing it to be withdrawn from the world market? ${ }^{21}$ Is it time for a new formulation?

As a result of marked changes in the organsation of health services and increases in knowledge about the genesis and management of disease, there is good reason to question the differentiation of prevention from other aspects of health care.

Clinical settings are increasingly moving towards populationbased medicine. As clinical practices become larger, with defined populations, the realities of individual-based medical care now have to confront the principles of population-based care. Increased risk of an event based upon the presence of a "predisposing factor" with high relative risk may no longer be the main criterion for intervention. The "event" may be too uncommon in the population and hence not practical as a priority. Alternatively, the intervention to reduce excess risk, while useful based on statistical associations in clinical trials, may not be useful in other population groups not included in the trial. ${ }^{22}$ A prime example is the utility of statins for "prevention" of recurrent myocardial infarct in men and the absence of evidence for their utility in either primary or secondary prevention in women. ${ }^{23}$ The presence of sex differences in screening for abdominal aortic aneurysm provides another example; screening might be useful in at least some men but is not useful in women. ${ }^{24}$ Clinical trials might not identify population group differences as most, by virtue of their design, are unable to examine the range of individual and community characteristics that could influence responsiveness to interventions.

A preventive activity might be justified in one setting but not in another just because of differences in prevalence, even though the relative risk based on the exposure is the same. What works in one clinical setting may not work in another, even when the relative risk of a characteristic is the same. Population-based studies of the predictive value of exposures consistently find lower likelihood of disease in the presence of a risk factor than do clinically based studies. ${ }^{25}{ }^{26}$ As clinical settings are becoming more and more population based, policies regarding the utility of preventive measures are likely to require change.

Perhaps the biggest threat to the concept of prevention, however, is the progressive lowering of thresholds for "predisease", particularly hypertension, serum cholesterol and blood sugar. With current thresholds, $97 \%$ of all US adults aged 50 and over have one or more of these three risk factors, but only $8 \%$ of cardiovascular disease will occur in individuals with any combination of them. The United States Preventive Services Task Force (USPSTF) has yet to update its recommendations for people with the changed definition of these conditions. ${ }^{12}$ Encouraged by interests vested in selling more medications for "prevention" and more medical devices for testing, the pressure for increasing "prevention" in clinical care directed at individuals is inexorable-even though it is not well supported by evidence in populations of patients. ${ }^{27}$

The focus of prevention has always been on "diseases". As the concept of "disease" is changing over time (with lowering thresholds for designation of "disease") ${ }^{28}$ and risk factors are considered equivalent to disease, the boundaries between prevention and cure are becoming increasingly indistinct. Physicians, as a profession, have always had the power to define "diseases" and stages of diseases..$^{29}{ }^{30}$ For example, the current definition of heart failure ${ }^{31}$ includes four stages. Obesity constitutes stage $\mathrm{A}$, even in the absence of symptoms or structural changes in the heart. Stage B also constitutes being "at risk of heart failure". Only stages C and D constitute evident heart failure. States A and B are preheart failure - a "diagnosis" justifying medication. When drugs are promoted for prevention and the number of patients at risk is very large, the expanded exposure to the drug may lead to important harm. ${ }^{32}$ The increasing attention to iatrogenic causes of ill health and the resulting addition of "quaternary prevention" also point to the need to explicitly include iatrogenesis as an influence on ill health.

Recommendations for clinical preventive services still focus largely on the results of analyses of relative risk in individuals not necessarily representative of the population or subpopulations. ${ }^{33}$ Furthermore, recommendations for risk factor screening are made one by one, despite evidence that risk factors are not independent of each other. On average, adult patients in the US in the mid-1990s were estimated to have approximately 12 risk factors requiring approximately 24 preventive services-even before the explosion of the concept of risks. ${ }^{34} \mathrm{~A}$ more recent analysis, recognising some of the limitations of estimates of benefit, set several priorities for clinical prevention in the total population based on "preventable burden" and cost-effectiveness; none involved medications other than immunisations. ${ }^{35}$

The major challenges in setting policy for interventions to reduce illness seem to be:

1. avoiding the fallacy that risks are independent

2. the importance of setting priorities based upon frequency of the desired outcome in populations

3. the importance of setting priorities to reduce inequities in health in populations as well as or in preference to improving effectiveness in individuals

4. considering when it is more efficient (and perhaps more effective and equitable) to prioritise interventions to populations, including defined populations in the clinical sector

5. placing priority on improving health generically (as, for example, by reduction in overall and age-specific death rates, by improvements in life expectancy and by reductions in disability and in perceived poor health) rather than disease by disease $e^{33} 3637$

6. taking into account the patient's perspective in clinical prevention $^{38}$

7. avoiding incentives for physician activities that are measurable but of low priority for population health gain. ${ }^{39}$

A framework (table 1) for conceptualising reductions in the occurrence and severity and progression of disease would both abandon the confusing and outmoded approach to prevention and substitute a framework that distinguishes societal from individual interventions on the one hand and, on the other, distinguishes risks that result from suboptimal physical, social, health service and individual environments.

The increasing world focus on achieving equity in health ${ }^{40}$ is likely to bring greater pressure on advocates of "prevention" to more clearly delineate the scope of the concept and the nature of ameliorative efforts. If inequities in health are to be reduced or eliminated, the full range of possible interventions needs to be specified and choices made about priorities. The "web" of influences on health and on inequity in health is very broad, ranging from societal influences to policy influences, to 
Table 1 Levels and types of interventions to improve health*

\begin{tabular}{|c|c|c|}
\hline & Societal (population) level & Individual level \\
\hline $\begin{array}{l}\text { Physical } \\
\text { environment }\end{array}$ & $\begin{array}{l}\text { Environmental planning, monitoring, } \\
\text { regulation }\end{array}$ & $\begin{array}{l}\text { Responsible use of } \\
\text { environmental resources }\end{array}$ \\
\hline $\begin{array}{l}\text { Social } \\
\text { environment }\end{array}$ & Public advocacy, community mobilisation & Promotion of solidarity \\
\hline \multirow[t]{2}{*}{$\begin{array}{l}\text { Health services } \\
\text { environment }\end{array}$} & Resource mobilisation/deployment & $\begin{array}{l}\text { Early recognition of } \\
\text { problems regardless of } \\
\text { their genesis }\end{array}$ \\
\hline & $\begin{array}{l}\text { Information systems: collection, analysis } \\
\text { and dissemination for early identification } \\
\text { of problems and iatrogenesis }\end{array}$ & \\
\hline $\begin{array}{l}\text { Personal } \\
\text { environment }\end{array}$ & Genetic engineering & $\begin{array}{l}\text { Responsible stewardship } \\
\text { of one's health }\end{array}$ \\
\hline
\end{tabular}

*Locus of responsibility may vary from one jurisdiction to another but must be explicit and with accountability.

Source: Sheridan et al. ${ }^{38}$

community influences, to social relationships and to individual characteristics (innate as well as developmental, biological and behavioural). ${ }^{41}$ The possibilities for prevention are vast, involving very different types of approaches and constituencies because prevention involves virtually every sector of societal, social and individual endeavour.

It would be presumptuous to suggest that the term "prevention", which is so widely entrenched in medical thinking and supported by committed constituencies, could be discarded even if its vagueness is largely dysfunctional. It may be possible, however, to seek agreement on two critical aspects: a focus on population health and a focus on reducing disparities (inequities) in health.

"Population based" is no longer synonymous with "public health". Public health constitutes societal approaches to improving health, but "population based" means that evidence is derived from population statistics rather than from individual patients in unrepresentative clinical practice. Priorities for action are made on the basis of population-based evidence, which includes consideration of attributable risk as well as relative risk. The hazards of clinical prevention have been catalogued $^{42}$ and include such considerations as absence of evidence relevant to setting priorities and imprecision of rules allowing prediction of benefit; competition of clinical preventive activities with care of manifest problems; and compromised health resulting from preventive interventions. In view of the systematic dismantling of the public health infrastructure in at least some countries with concomitant increases in the scope and influence of clinical services, an adoption of population principles for clinical services would appear to be in order.

A fresh approach to prevention requires a refocusing of attention from evidence relevant to individuals to evidence relevant to populations-even those in clinical settings. Preventive activities have widely differing effectiveness; in choosing preventive activities, impact on populations and especially on the distribution of health (ie equity in health) within populations should take precedence. The distinction between population and clinical bases for health policy decisions is made clear by the following example. Individual risk factors for tuberculosis in Russia in order of degree of risk are: low household wealth; incarceration in prison or detention; drug misuse; financial insecurity; unemployed; overcrowded living; living with a person with tuberculosis; and heavy drinking. Population risk factors are different. The two major risks in the population are unemployment and consumption of raw milk. ${ }^{43}$ Policy decisions should be targeted primarily at risks that are common in the population, not at the extent of increased risk in individuals.

The lagging performance of the US on virtually every health indicator may be testimony to the high-profile but inadvisable concentration on interventions based on managing risks in individual patients. In the same way, reductions in inequities in health are likely to be intractable in countries where the focus of attention is on the receipt of "indicated care" in largely affluent populations who have access to care. The success of prevention is ultimately measured in population health measures and, increasingly, on reducing avoidable differences in health across population subgroups, rather than on meeting professional criteria for "quality of care".

In its focus primarily on professionally defined disease entities, the practice of medicine (and particularly the practice of "prevention") is moving increasingly further from its roots in the care of patients-true "patient-centred care". ${ }^{29}$ In view of the large extent of coexistence of diseases (multimorbidity) in individuals and in subpopulations, the increasing rates of adverse events that have no representation in disease statistics, the variability in impact on functioning even within diseases and the disability and dysfunction in the absence of conventional disease labels, there is an urgent need for measures of health that cut across diseases and disease categories (http:// www.acg.jhsph.edu). Generic measures based on impact can also be used to good advantage; examples are death rates, disability rates, years of potential life lost, low birthweight and measures such as health-adjusted life expectancy and disabilityadjusted life expectancy.

The major challenge is to set priorities based on likely improvements in overall (not disease-specific) health in populations and population subgroups, by conceptualising prevention as a set of activities. The ambitious US-led Goals for the Nation lacked focus on activities driven by the need to improve health more broadly than its current focus on specific diseases. The more recent activities-directed quality objectives (with consequent payment for performance) are activities without health or equity in health goals. The need to ensure better health for populations (especially in developing countries) and better distribution of health (in all countries) demands a refocus on health rather than on preventing specific diseases.

As policy decisions about prevention and care often compete with decisions made on the basis of equity, calculation of the costs and benefits of various preventive strategies should be done both ways, including a cost-consequences approach, in order to make explicit the nature of decisions that societies must make. ${ }^{44}$

\section{CONCLUSIONS}

A renewed (and possibly renamed) conceptualisation of "prevention" would consider:

1. Population orientation (even for clinical medicine)

2. Population-attributable risk rather than individual (relative) risk

3. Morbidity burden rather than disease burden

4. Tandem estimation of the benefits and costs of strategies to improve both population health and the distribution of health within populations

5. Improving overall health rather than disease prevention as a major goal. There may never be agreement on priorities for prevention or what "prevention" is, but there can be agreement on what should be achieved, in the context of equity and maximisation of population health. 
6. Avoiding past overestimations of the utility of individual risk factors in causing ill health in populations, even those addressing genetic predispositions.

Emerging population-based information systems make it eminently possible to merge "prevention" and "care", providing a new focus on the possibilities for achieving better and more equitable distribution of health. ${ }^{45}$

Competing interests: None declared.

\section{REFERENCES}

1. Clark DW, MacMahon B. Preventive medicine. Boston, MA: Little, Brown \& Co 1967

2. Nightengale E0, Cureton M, Kalmar V, et al. Perspectives on health promotion and disease prevention in the United States. Washington, DC: Institute of Medicine, National Academy of Sciences, 1978.

3. National Public Health Partnership. Preventing chronic disease: a strategic framework. Background paper. Melbourne, Australia: National Public Health Partnership, 2001.

4. Last JM. Dictionary of public health. New York, NY: Oxford University Press, 2006

5. Bentzen N. WONCA dictionary of general/family practice. Copenhagen, Denmark: Laegeforeningens Forlag, 2003.

6. Gofrit $\mathbf{O N}$, Shemer J, Leibovici D, et al. Quaternary prevention: a new look at an old challenge. Isr Med Assoc J 2000:2:498-500.

7. Association of State and Territorial Chronic Disease Program Directors Defining a role for public health in secondary/tertiary prevention of cardiovascular disease. Cited in Mensah GA, Dietz WH, Harris VB, et al. Centers for Disease Control and Prevention. Prevention and control of coronary heart disease and stroke nomenclature for prevention approaches in public health: a statement for public health practice from the Centers for Disease Control and Prevention. Am J Prev Med 2005:29(5 Suppl 1):152-7.

8. Stoltenberg C. Merging genetics and epidemiology: what is in it for public health? Scand J Public Health 2005;33:1-3.

9. Beaglehole R, Magnus $P$. The search for new risk factors for coronary heart disease: occupational therapy for epidemiologists? Int J Epidemiol 2002;31(6):1117-22.

10. Brotman DJ, Walker E, Lauer MS, et al. In search of fewer independent risk factors. Arch Intern Med 2005;165:138-45.

11. Skarabank P, McCormick J. Follies and fallacies in medicine. Glasgow: Tarragon Press, 1989

12. Kaplan RM, Ong M. Rationale and public health implications of changing $\mathrm{CHD}$ risk factor definitions. Annu Rev Public Health 2007:28:321-44.

13. World Health Organization. The World Health Report 2000. Health systems: improving performance. Geneva, Switzerland: World Health Organization, 2000.

14. Toon PD. Health checks in general practice. BMJ 1995;310:1083-4.

15. Laine C. The annual physical examination: needless ritual or necessary routine? Ann Intern Med 2002:136:701-3.

16. Chacko KM, Feinberg LE. Laboratory screening at preventive health exams: trend of testing. Am J Prev Med 2007;32:59-62.

17. Skinner JS, Coooper A, Feder GS. Secondary prevention for patients after a myocardial infarction: summary of NICE guidance. BMJ 2007;334:1112-13.

18. Ray JG, Kearon C, Yi O, Sheridan P, et al. Heart Outcomes Prevention Evaluation 2 (HOPE-2) investigators. Homocysteine-lowering therapy and risk for venous thromboembolism: a randomized trial. Ann Intern Med 2007;146:761-7.

19. Ferreira-Gonzalez I, Busse JW, Heels-Ansdell D, et al. Problems with use of composite end points in cardiovascular trials: systematic review of randomised controlled trials. BMJ 2007;334:786-92.

20. Freemantle $\mathbf{N}$, Calvert $M$. Composite and surrogate outcomes in randomised controlled trials. BMJ 2007;334:756-7.

21. Farmer JA. Learning from the cerivastatin experience. Lancet 2001:358:1383-5.
22. Feinstein AR. The problem of cogent subgroups: a clinicostatistical tragedy. J Clin Epidemiol 1998;51:297-9

23. Kendrick M. Should women be offered cholesterol lowering drugs to prevent cardiovascular disease? BMJ 2007:334:983.

24. Cosford PA, Leng GC. Screening for abdominal aortic aneurysm. Cochrane Database of Systematic Reviews 2007:(2):CD002945. doi: 101002/14651858.CD002945.pub2.

25. Boeke AJ, van Bergen JE, Morre SA, et al. [The risk of pelvic inflammatory disease associated with urogenital infection with Chlamydia trachomatis; literature review]. Ned Tijdschr Geneeskd 2005:149:878-84.

26. Sox HC. Decision-making: a comparison of referral practice and primary care. J Fam Pract 1996:42:155-60.

27. Sackett DL. The arrogance of preventive medicine. Can Med Assoc J 2002;167:363-4.

28. Heath I. Combating disease mongering: daunting but nonetheless essential. PLOS Med 2006;3:e146.

29. Gervas J, Perez Fernandez M. [Limits to the power of medicine to define disease and risk factor, and quaternary prevention]. Gac Sanit 2006;20(Suppl 3):66-71.

30. Gervas J. Screening for serious illness. Limits to the power of medicine. Eur J Gen Pract 2002:8:47-9.

31. Hunt SA, Abraham WT, Chin MH, et al. ACC/AHA 2005 Guideline update for the diagnosis and management of chronic heart failure in the adult: a report of the American College of Cardiology/American Heart Association Task Force on Practice Guidelines (Writing committee to update the 2001 guidelines for the evaluation and management of heart failure): developed in collaboration with the American College of Chest Physicians and the International Society for Heart and Lung Transplantation: endorsed by the Heart Rhythm Society. Circulation 2005:112:e154-e235.

32. Montori VM, Isley WL, Guyatt GH. Waking up from the DREAM of preventing diabetes with drugs. BMJ 2007:334:882-4.

33. Mangin D, Sweeney K, Heath I. Preventive health care in elderly people needs rethinking. BMJ 2007;335:285-7

34. Medder JD, Kahn NB Jr, Sussman JL. Risk factors and recommendations for 230 adult primary care patients, based on US Preventive Services Task Force guidelines. Am J Prev Med 1992:8:150-3.

35. Maciosek MV, Coffield AB, Edwards NM, et al. Priorities among effective clinical preventive services: results of a systematic review and analysis. Am J Prev Med 2006;31:52-61.

36. Tinetti ME, Fried T. The end of the disease era. Am J Med 2004;116(3):179-85.

37. De Maeseneer J, Willems S, De Sutter A, et al. Primary health care as a strategy for achieving equitable care: a literature review commissioned by the Health Systems Knowledge Network. WHO Health Systems Knowledge Network, 2007. http://www. wits.ac.za/Academic/Centres/CHP/Collaboration/HSKN.htm laccessed 20 Aug 2007).

38. Sheridan SL, Harris RP, Woolf SH, shared decision-making group of the US preventive services task force. Shared decision making about screening and chemoprevention: a suggested approach from the US Preventive Services Task Force. Am J Prev Med 2004:26:56-66.

39. Fleetcroft R, Cookson R. Do the incentive payments in the new NHS contract for primary care reflect likely population health gains? J Health Serv Res Policy 2006:11:27-31.

40. Lee J-W. (Jong-wook L) Global health improvement and WHO: shaping the future Lancet 2003:362:2083-8.

41. Starfield B. Pathways of influence on equity in health. Soc Sci Med 2007;64:135562.

42. Gervas J, Starfield B, Heath I. Cautions in clinical prevention. Lancet 2008; in press

43. Coker R, McKee M, Atun R, et al. Risk factors for pulmonary tuberculosis in Russia case-control study. BMJ 2006;332:85-7.

44. Detsky AS, Laupacis A. Relevance of cost-effectiveness analysis to clinicians and policy makers. JAMA 2007:298:221-4.

45. Ottawa Charter for Health Promotion. First International Conference on Health Promotion. Ottawa, Canada, 17-21 Nov 1986. http://who.int/hpr/NPH/docs/ ottawa charter hp.pdf (accessed 28 Sep 2007). 